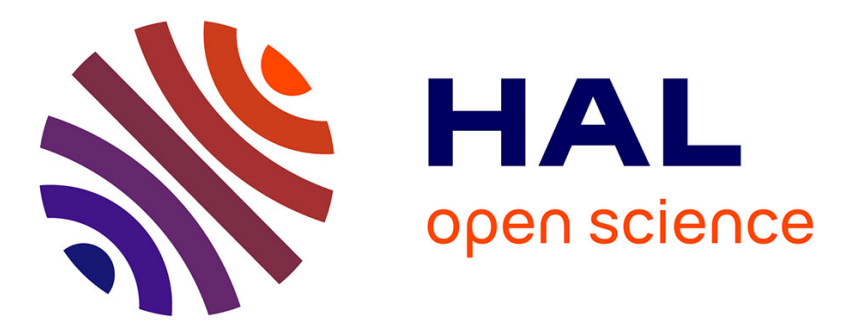

\title{
Slip systems of Cu2O by Knoop hardness anisotropy measurement
}

\author{
A. Audouard, B. Pellissier, J. Castaing
}

\section{To cite this version:}

A. Audouard, B. Pellissier, J. Castaing. Slip systems of Cu2O by Knoop hardness anisotropy measurement. Journal de Physique Lettres, 1977, 38 (1), pp.33-35. 10.1051/jphyslet:0197700380103300 . jpa-00231316

\section{HAL Id: jpa-00231316 https://hal.science/jpa-00231316}

Submitted on 1 Jan 1977

HAL is a multi-disciplinary open access archive for the deposit and dissemination of scientific research documents, whether they are published or not. The documents may come from teaching and research institutions in France or abroad, or from public or private research centers.
L'archive ouverte pluridisciplinaire HAL, est destinée au dépôt et à la diffusion de documents scientifiques de niveau recherche, publiés ou non, émanant des établissements d'enseignement et de recherche français ou étrangers, des laboratoires publics ou privés. 


\title{
SLIP SYSTEMS OF $\mathrm{Cu}_{2} \mathrm{O}$ BY KNOOP HARDNESS ANISOTROPY MEASUREMENT
}

\author{
A. AUDOUARD, B. PELLISSIER and J. CASTAING \\ Laboratoire de Physique des Matériaux, C.N.R.S. Bellevue, 92190 Meudon, France
}

(Reçu le 7 octobre 1976, accepté le 22 novembre 1976)

\begin{abstract}
Résumé. - Des essais de microdureté Knoop ont été effectués à température ambiante sur des monocristaux d'oxyde cuivreux $\mathrm{Cu}_{2} \mathrm{O}$. L'analyse de l'anisotropie de dureté a montré que le système de glissement déclenché est le système $\{110\}\langle 1 \overline{1} 0\rangle$.
\end{abstract}

\begin{abstract}
Knoop microhardness tests have been performed at room temperature on $\mathrm{Cu}_{2} \mathrm{O}$ cuprous oxide single crystals. Hardness anisotropy analysis indicates that $\{110\}\langle 1 \overline{1} 0\rangle$ is the operative slip system.
\end{abstract}

1. Introduction. $-\mathrm{Cu}_{2} \mathrm{O}$ cuprous oxide has a cubic structure; the oxygen atoms are at the nodes of a body centered cubic lattice and the copper atoms at those of a face centered cubic lattice displaced $a / 4$ (111) from the oxygen sub-lattice.

A few studies of plastic deformation have been performed in particular by Vagnard et al. [1], M. Martinez-Clemente et al. [2] and G. T. Villasenor [3]. M. Martinez Clemente studied constant strain rate compression of $\mathrm{Cu}_{2} \mathrm{O}$ single crystals which were brittle at room temperature and were deformed plastically in a temperature range between $400^{\circ} \mathrm{C}$ $(0.45 \mathrm{Tm})$ and $800^{\circ} \mathrm{C}(0.7 \mathrm{Tm})$. When the stress is applied parallel to a $\langle 100\rangle$ direction, the slip system is $\{110\}\langle 1 \overline{1} 0\rangle$ while when applied parallel to a $\langle 110\rangle$ direction, the slip system is $\{100\}\langle 010\rangle$. $A\{110\}$ slip plane with an unknown slip direction seems to be also operative in the latter case. Vagnard et al. have only observed the $\{100\}\langle 010\rangle$ slip system. G. T. Villasenor studied the deformation of single crystals and polycrystals at room temperature under hydrostatic pressure. The observed slip systems are $\{110\}\langle 1 \overline{1} 1\rangle$ for stress applied along $\langle 100\rangle$ and $\{112\}\langle 11 \overline{1}\rangle$ for stress applied along $\langle 311\rangle$.

The results of G. T. Villasenor, obtained at room temperature, are different from those of M. MartinezClemente and Vagnard, obtained at higher temperatures. So, it seemed interesting to perform mechanical tests at room temperature to obtain further information on the slip systems which are operative during the plastic deformation of $\mathrm{Cu}_{2} \mathrm{O}$. For this purpose, we used the microhardness test.
2. Experimental procedure. - Single crystal preparation has been described previously [2, 4]. Samples are cut with an Isomet low speed saw after orientation by the Lauie method [5]. Before mechanical testing, the samples are mechanically polished, then chemically polished in a mixture of $70 \%$ orthophosphoric acid and $30 \%$ nitric acid. Microhardness tests are performed using a Knoop indenter mounted in a Leitz miniload hardness apparatus $\left({ }^{1}\right)$. A 0.196 da $\mathrm{N}$ load is applied for $10 \mathrm{~s}$. The Knoop hardness values $H_{\mathrm{k}}$ are calculated from the empirical formula :

$$
H_{\mathrm{k}}=\frac{F}{A}=14.23 \frac{F}{L^{2}} \text { da } \mathrm{N} \mathrm{mm}^{-2}
$$

where $F$ is the indenting load (da N), $A$ is the indentation area $\left(\mathrm{mm}^{2}\right)$ and $L$ is the indentation length $(\mathrm{mm})$.

3. Hardness anisotropy analysis. - Hardness anisotropy results are analysed using the Brookes et al. relationship [6] which is a modification of that due to Daniel and Dunn [7]. This relationship is established with the assumption that the indenter develops a tensile force on a cylindrical element of material parallel to the line of steepest slope on the considered facet :

$$
\sigma_{\mathrm{g}}=\sigma_{0} \cos \varphi \cos \lambda \frac{\cos \psi+\sin \gamma}{2}
$$

( ${ }^{1}$ The use of the apparatus of the Equipe de Mécanique des surfaces of C.N.R.S. Bellevue is acknowledged. 
Where $\sigma_{\mathrm{g}}$ is the mean effective resolved shear stress, $\sigma_{0}$ is the applied stress,

$\varphi$ is the angle between the tensile axis and the slip plane normal,

$\lambda$ is the angle between the tensile axis and the slip direction,

$\psi$ is the angle between the axis parallel to the facet and perpendicular to the tensile axis and the axis of rotation of slip plane,

$\gamma$ is the angle between the axis parallel to the facet and perpendicular to the tensile axis and the slip direction.

It is possible to calculate $\sigma_{\mathrm{g}} / \sigma_{0}$ values for the four indenter facets [6] in order to obtain the variations of $\sigma_{\mathrm{g}} / \sigma_{0}$ with the orientation of the long axis of the indenter, for a given slip system and a crystallographic face. The ratio $\sigma_{\mathrm{g}} / \sigma_{0}$ has a variation opposite to that of the hardness $H_{k}$ i.e. it is an increasing function of the inverse of the hardness $H_{\mathrm{k}}^{-1}$. The comparison of the experimental $H_{\mathrm{k}}^{-1}$ and the calculated $\sigma_{\mathrm{g}} / \sigma_{0}$ curves allows the slip system to be deduced.

4. Experimental results. - The $\sigma_{\mathrm{g}} / \sigma_{0}$ curves were established for the four slip systems observed in $\mathrm{Cu}_{2} \mathrm{O}$ for indentations on a (001) face (Fig. 1) and a (011) face (Fig. 2). The $\sigma_{\mathrm{g}} / \sigma_{0}$ curve for the $\{110\}\langle 001\rangle$ slip system was also established for a (011) face (Fig. 2).
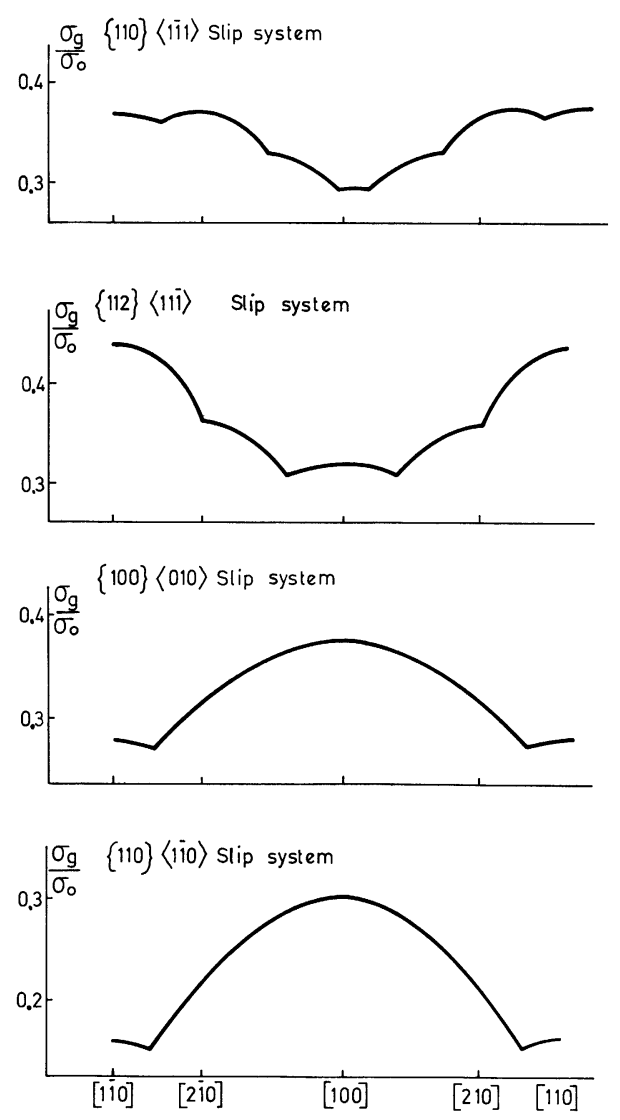

FIG. 1. - Calculated variations of $\sigma_{\mathrm{g}} / \sigma_{0}$ with orientation of Knoop indenter long axis for the (001) surface.
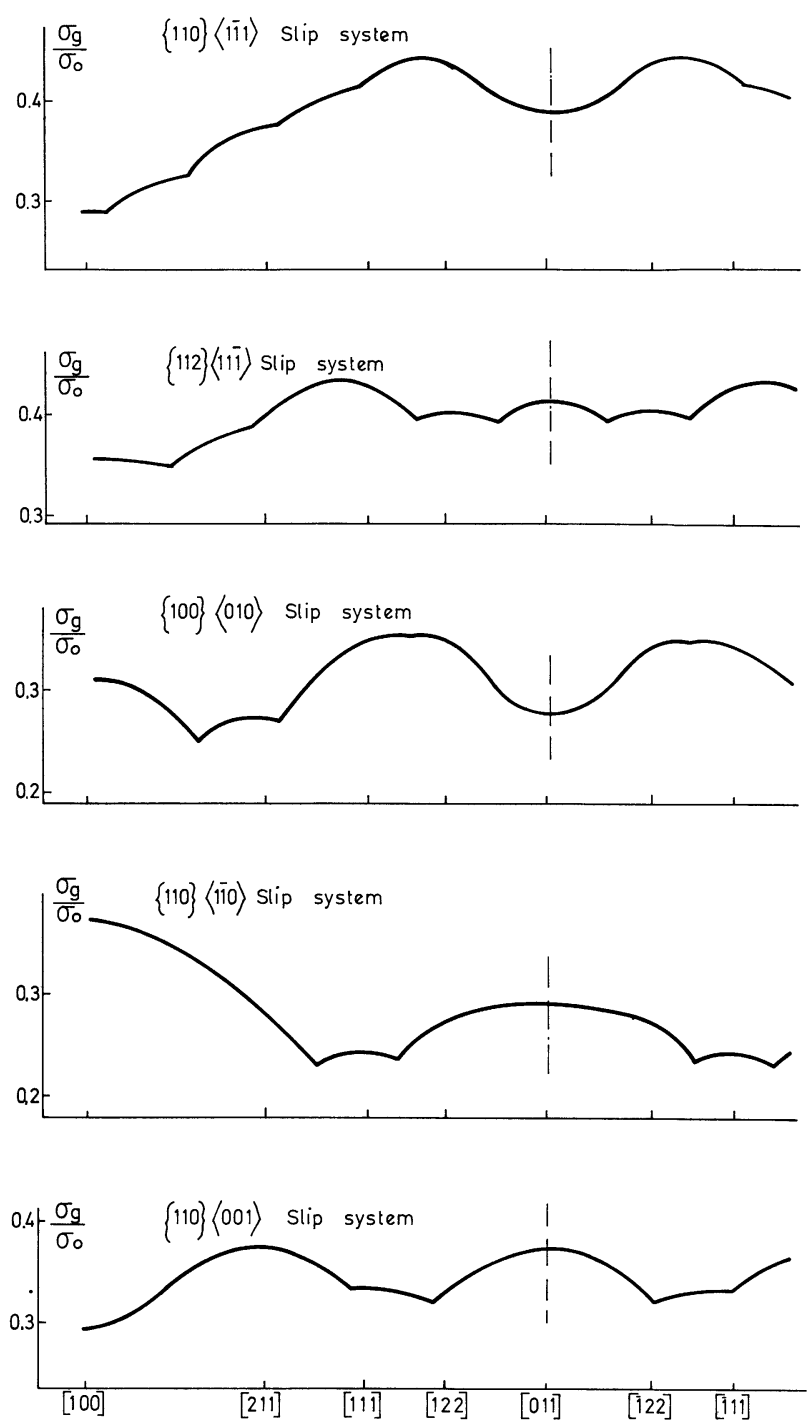

FIG. 2. - Calculated variations of $\sigma_{\mathrm{g}} / \sigma_{0}$ with orientation of Knoop indenter long axis, for the $(0 \overline{1} 1)$ surface.

4.1 (001) SURFACE. - The $H_{\mathrm{k}}^{-1}$ curve was established by making repeated indentations after rotations of two degrees (Fig. 3). The comparison with the $\sigma_{\mathrm{g}} / \sigma_{0}$ curves indicates that the $\{110\}\langle 1 \overline{1} 1\rangle$ and $\{112\}\langle 11 \overline{1}\rangle$ slip systems do not operate in plastic deformation at room temperature, but does not allow

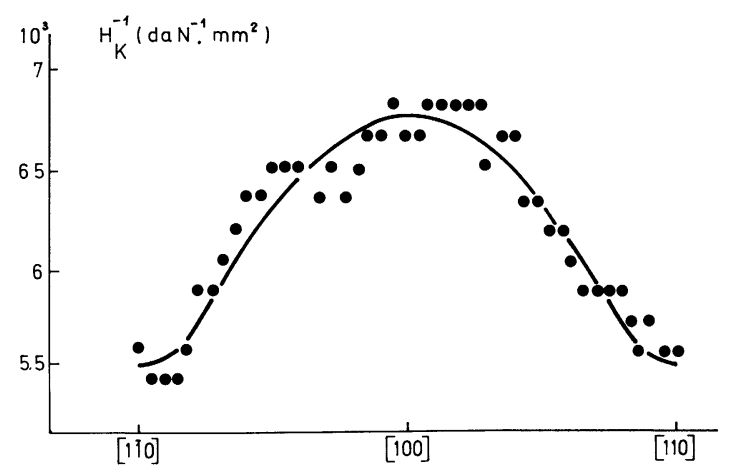

Fig. 3. - Reciprocal of Knoop hardness for the (001) surface. 


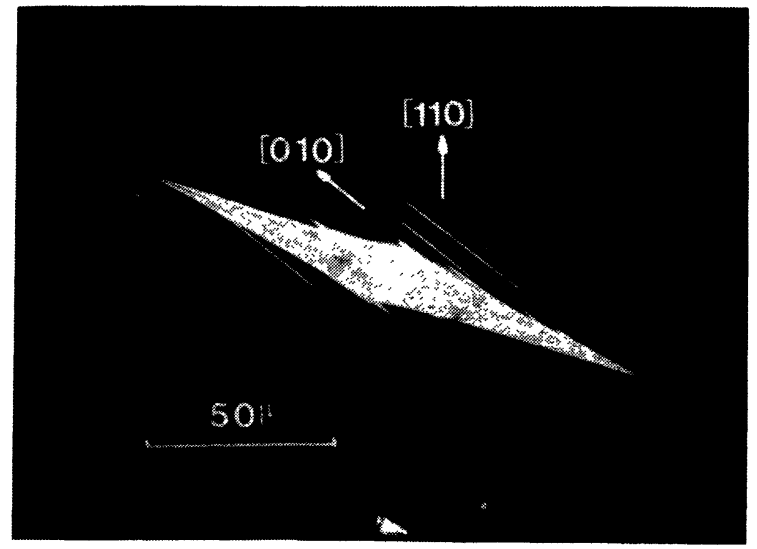

Fig. 4. - Knoop indentation on the (001) surface showing slip lines (unetched).

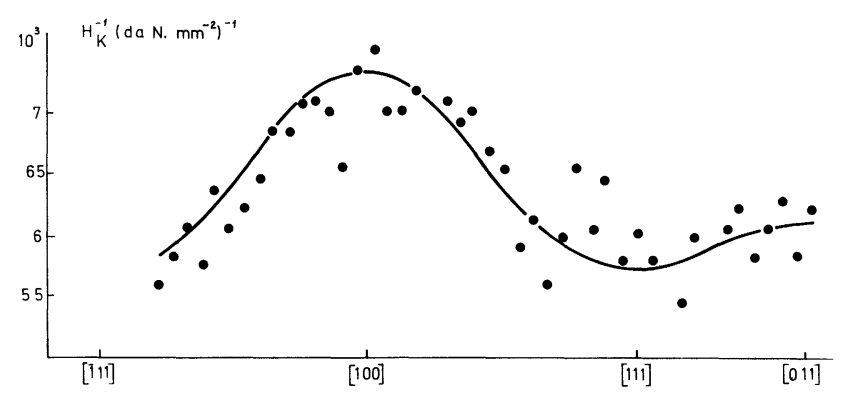

Fig. 5. - Reciprocal of Knoop hardness for the (01̄1) surface.

one to determine which slip system $\{110\}\langle 1 \overline{1} 0\rangle$ or $\{100\}<010\rangle$ operates.

Slip lines developed around indentations have $\langle 100\rangle$ directions. They correspond to either $\{100\}$ slip planes or $\{110\}$ slip planes (Fig. 4). No conclusion can be drawn. This difficulty is eliminated with experiments on the (011) surface.

4.2 (011) SURFACE. - The $H_{\mathbf{k}}^{-1}$ curve was established by making repeated indentations after rotations of three degrees (Fig. 5). The comparison with

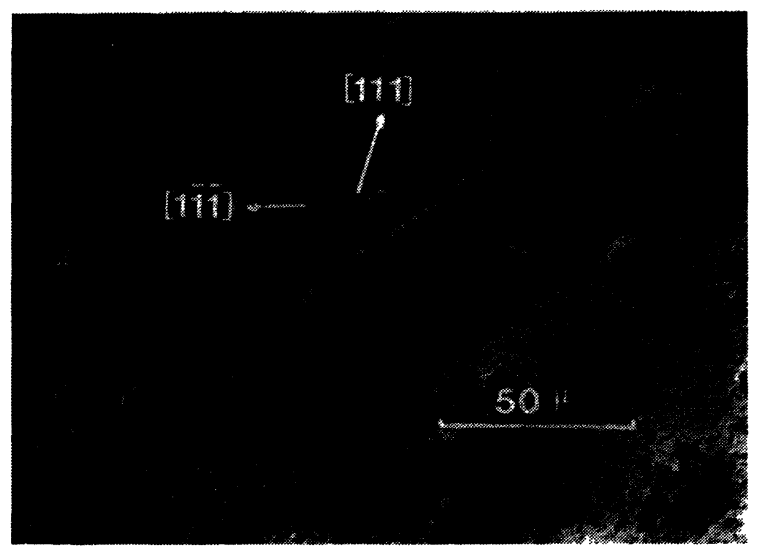

FIG. 6. - Knoop indentation on the $(0 \overline{1} 1)$ plane showing slip lines (unetched).

the $\sigma_{\mathrm{g}} / \sigma_{0}$ curves indicates that $\{110\}\langle 1 \overline{1} 0\rangle$ is the slip system. This is confirmed by the observation of the slip line directions which are $\langle 111\rangle$ (Fig. 6).

5. Discussion. - The slip system operating at room temperature during Knoop microhardness testing is $\{110\}\langle 1 \overline{1} 0\rangle$. This slip system is one of those observed by M. Martinez-Clemente [2] at high temperature. The plastic deformation under an indenter is usually regarded as performed under hydrostatic pressure [8]; however the slip systems, found by G. T. Villasenor at room temperature under hydrostatic pressure, are not operative in the microhardness test. The $\{110\}\langle 001\rangle$ slip system seems to be inoperative in both our experiments and in those of Martinez-Clemente et al. [2]. The $\{100\}\langle 101\rangle$ slip system has, at high temperature, a strength lower than that of the $\{110\}\langle 110\rangle$. This is different from the results at room temperature since only the $\{110\}\langle 110\rangle$ system seems to operate in microhardness tests. So, a change in mechanical behaviour between room temperature and $0.45 \mathrm{Tm}$ is expected. This change might be studied by performing microhardness tests at various temperatures.

\section{References}

[1] Vagnard, G. and Washburn, J., J. Am. Ceram. Soc. 51 (1968) 88

[2] Martinez-Clemente, M., Bretheau, T. and Castaing, J., J. Physique 37 (1976) 895.

[3] VillasenoR, G. T., Ph. D. thesis, Case Western Reserve University, Cleveland (1972).

[4] Schmidt Whitley, R. D., Martinez-Clemente, M. and Revcolevschi, A., J. Cryst. growth 23 (1974) 113.
[5] Bretheau, T., Cadoz, J., Dolin, C., Pellissier, B. and Spendel, M., Ind. Céram. 694 (1976) 293.

[6] Brookes, C. A., O’Neill, J. B. and Redfern, B. A. W., Proc. R. Soc. 322 (1971) 73-88.

[7] Daniels, F. W. and Dunn, C. G., Trans. Am. Soc. Met. 41 (1949) 419.

[8] The Science of hardness testing and its research applications, Edited by Westbrook J. H. and Conrad H., American Society for Metals (1973) p. 22. 